Article

\title{
Biological Effects of Paullinia cupana (Guarana) in Combination with Whole-Body Vibration Exercise in Wistar Rats
}

\author{
André L.B.D. Cardoso ${ }^{1,2}{ }^{\mathbb{D}}$, Éric H.F.F. Frederico ${ }^{1}$, Carlos A.S. Guimarães ${ }^{1}$, Aline Reis-Silva ${ }^{1,3}$, \\ Eliane de Oliveira Guedes-Aguiar ${ }^{1,4}$, Arlete Francisca Santos ${ }^{1}$, \\ Márcia Cristina Moura-Fernandes ${ }^{1,2}$, Luiz Felipe Ferreira-Souza ${ }^{1}$ (D), Tiago Eduardo-Santos ${ }^{1}$, \\ Diego Eduardo-Santos ${ }^{1}$, Rubens Guimarães Mendonça ${ }^{1}$, Danúbia da Cunha de Sá-Caputo ${ }^{1}$ (D), \\ Laisa Liane Paineiras-Domingos ${ }^{1,3} \mathbb{D}$, Redha Taiar $1,5, * \mathbb{D}$, Nasser R. Asad ${ }^{1}$ \\ and Mario Bernardo-Filho ${ }^{1}$ (D) \\ 1 Laboratório de Vibrações Mecânicas e Práticas Integrativas, Departamento de Biofísica e Biometria, \\ Instituto de Biologia Roberto Alcantara Gomes e Policlínica Américo Piquet Carneiro, Universidade do \\ Estado do Rio de Janeiro, Rio de Janeiro RJ 20950-003, Brazil; andreluisdionizio@hotmail.com (A.L.B.D.C.); \\ ericfrederico@msn.com (É.H.F.F.F.); carlosalbertolinco@hotmail.com (C.A.S.G.); \\ fisio.alinereis@hotmail.com (A.R.-S.); ellianeguedes@gmail.com (E.d.O.G.-A.); \\ fisioarlete@hotmail.com (A.F.S.); marciafernandesfisio@hotmail.com (M.C.M.-F.); \\ lumadaragu@gmail.com (L.F.F.-S.); tesantos17@gmail.com (T.E.-S.); eudardosantos17@gmail.com (D.E.-S.); \\ rubens_fisio@hotmail.com (R.G.M.); dradanubia@gmail.com (D.d.C.d.S.-C.); laisanit@gmail.com (L.L.P.-D.); \\ nasser.ribeiro@gmail.com (N.R.A.); bernardofilhom@gmail.com (M.B.-F.) \\ 2 Programa de Pós-graduação em Fisiopatologia Clínica e Experimental, Faculdade de Ciências Médicas, \\ Universidade do Estado do Rio de Janeiro, Rio de Janeiro RJ 20551-030, Brazil \\ 3 Programa de Pós-graduação em Saúde, Medicina Laboratorial e Tecnologia Forense, Universidade do Estado \\ do Rio de Janeiro, Rio de Janeiro RJ 20551-030, Brazil \\ 4 Programa de Pós-graduação em Ciências Médicas, Faculdade de Ciências Médicas, Universidade do Estado \\ do Rio de Janeiro, Rio de Janeiro RJ 20551-030, Brazil \\ 5 Groupe de Recherche En Sciences Pour I'Ingénieur, Université de Reims, 51100 Reims, France \\ * Correspondence: redha.taiar@univ-reims.fr
}

Received: 26 December 2019; Accepted: 30 January 2020; Published: 7 February 2020

check for updates

\begin{abstract}
In addition to its nutritional value, Paullinia cupana (guarana) is commonly used in traditional medicine, known for its stimulant and medicinal properties. This investigation evaluated the effects of a guarana extract in combination with whole-body vibration (WBV) exercises on Wistar rats. Rats (male, $\mathrm{n}=20$ ) were divided into the following four groups: control (CON), treated with guarana (GUA), submitted to $50 \mathrm{~Hz}$ of WBV (WBV-E), treated with guarana and submitted to $50 \mathrm{~Hz}$ of WBV (GUA + WBV-E), daily for 6-weeks. Guarana altered $(p<0.05)$ the uptake of the radiopharmaceutical sodium pertechnetate $\left(\mathrm{Na}^{99} \mathrm{TcO}_{4}\right)$ in muscle. Additionally, it modified the stool consistency, and in combination with WBV decreased the food intake without modifying body mass. The levels of calcium increased in the groups submitted to WBV exercises (WBV-E and GUA + WBV-E) as compared with the GUA group. The outcomes provide additional evidence of the biological effects of guarana separately or in combination with WBV and supports the use of guarana as a functional food.
\end{abstract}

Keywords: guarana; whole-body vibration; biodistribution; body mass; food intake

\section{Introduction}

Natural products are widespread used for nourishment and therapeutic goals [1]. However, the mechanisms of their actions and their efficacy, in general, are not fully studied. [2]. 
Paullinia cupana (guarana) is a Brazilian plant (subfamily Sapindoideae) known for its stimulant and medicinal properties [3,4]. Guarana has been associated with diverse pharmacological properties, such as antiproliferative [5], anti-inflammatory [6], antioxidant, and cardioprotective [4,7,8]. Moreover, it would have cytoprotective [4], energetic, thermogenic [9], antidepressant [10], and anxiolytic [11] qualities (Figure 1). This natural product is commonly consumed by dissolving the powder of its seeds in water or in association with other herbal drugs. Currently, guarana is exploited on a large scale by food supplements and the soft drinks industry for its effects on physical performance and body mass control [4].

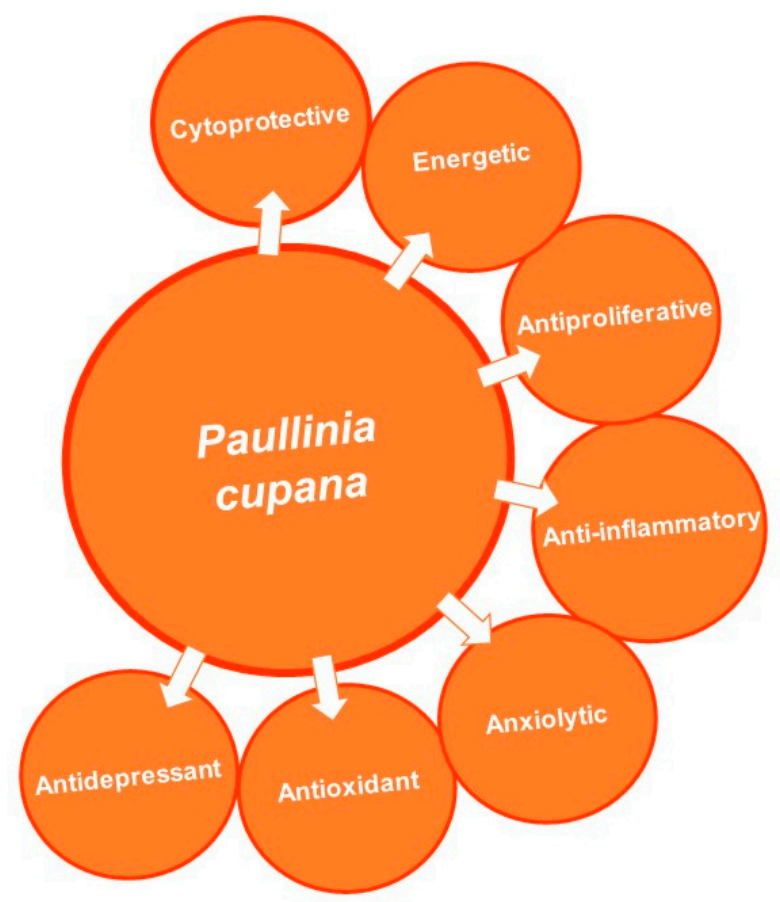

Figure 1. Biological effects of Paullinia cupana.

The effects of some substances [12,13], including natural products [14,15], in association with whole-body vibration (WBV) exercise have been reported.

WBV is a type of exercise based on body adaptations to exposure to mechanical vibrations (MV) generated in a vibrating platform (VP) [16]. Rauch et al. [17] discussed various parameters associated with WBV exercises and, consequently, the frequency and peak-to-peak displacement, which are biomechanical parameters, must be selected and adapted to each person. Exposure time interspersed with a rest time must be also considered [17,18]. In controlled conditions, MV have generated WBV exercises in feasible, useful, and safe conditions [18]. In addition, WBV exercises have been considered as a noninvasive and non-pharmacological intervention [19]. The effects of WBV exercises on plasma concentrations of selected biomarkers have been studied in human beings [20-22]. In addition, some investigations have reported that WBV exercises could improve muscle activity, force and power [23,24], balance and flexibility [25], and cognitive performance [26].

Studies about the use of WBV exercises have increased over time [https://www.ncbi.nlm.nih.gov/ pubmed/?term=whole+body+vibration], and therefore the development of experimental models to assess the effects of this type of exercise in tissues and organs is desirable.

In experimental designs, the course of a drug (synthetic and natural) treatment or even WBV intervention can be evaluated with the effect on the radiopharmaceutical distribution $[27,28]$. Sodium pertechnetate $\left(\mathrm{Na}^{99} \mathrm{mcO}_{4}\right)$ is an example of a radiopharmaceutical used in clinical $[29,30]$ and experimental approaches [28,31,32]. Furthermore, parameters, such as food intake, body mass, and stool consistency could also support understanding the effects of the current intervention, 
as they have been verified with some medicinal plants, and Coriandrum sativum [15] and Chenopodium ambrosioides [33].

In view of the various actions of guarana extract in in vitro [2,5,6] and in vivo studies $[10,11,34]$, or even in preparations associated with other herbal drugs (chemical agents) [7], very little is known about the biological effects of guarana in association with a physical agent. These considerations were the motivation for the current investigation. Therefore, this work aimed to investigate the biological effects of guarana in Wistar rats in combination with WBV exercises $(50 \mathrm{~Hz}$, peak acceleration of $7.84 \mathrm{x}$ g) on physiological parameters such as the biodistribution of $\mathrm{Na}^{99 \mathrm{~m}} \mathrm{TcO}_{4}$, blood biochemical analysis, food intake, body mass, and stool consistency. Although it is unknown whether this combination has the potential to induce long-term changes on these factors, it is expected that this association would have alterations, and therefore the outcomes of this work would support the use of these agents for clinical purposes.

\section{Materials and Methods}

\subsection{Rats Conditions and Ethical Consideration}

Wistar rats (male, $\mathrm{n}=20,240$ to $280 \mathrm{~g}$, age 3 months) were kept in a room with an average temperature of $25^{\circ} \mathrm{C}$, a relative humidity about $55 \%$, and a light/dark cycle of $12 \mathrm{~h}$. Standard rodent diet and water ad libitum were offered to the animals. Institutional Ethics Committee for Animal Research at the Instituto de Biologia Roberto Alcantara Gomes (IBRAG) from Universidade do Estado Rio de Janeiro (UERJ) approved the investigation (CEUA/041/2013).

\subsection{Guarana Extract}

Dry extract of Paullinia cupana (guarana) was used (commercial, lot 0702014, validity up to October 2016, Chá e Cia Produtos Naturais, Jacareí, São Paulo, Brazil). Guarana (5 g) was added to deionized water $(20 \mathrm{~mL})$ and vortexed $(1 \mathrm{~min})$. Then, the preparation was centrifuged (clinical centrifuge, $2000 \mathrm{rpm}, 10 \mathrm{~min}$ ) and the supernatant (considered to be $250 \mathrm{mg} / \mathrm{mL}$ ) was separated. The control of the preparation of this aqueous extract was carried out (spectrophotometer analysis, extract with optical density at $500 \mathrm{~nm}$ at the concentration of $31.25 \mathrm{mg} / \mathrm{mL}$ ), as previously reported [15]. All the experiments were performed between July and August 2016.

\subsection{Experimental Steps}

Wistar rats ( $n=5$ per group) were divided randomly into the following groups (i) control (CON), (ii) treated with guarana (GUA), (iii) submitted to $50 \mathrm{~Hz}$ of WBV (WBV-E), and (iv) treated with guarana and submitted to $50 \mathrm{~Hz}$ of WBV (GUA + WBV-E), as shown in Figure 2. Daily, for 6 weeks (40 days) the CON group received [35] $1.0 \mathrm{~mL}$ of deionized water and the GUA group received $1.0 \mathrm{~mL}$ of aqueous extract of guarana at $250 \mathrm{mg} / \mathrm{mL}$ by gavage. Furthermore, the WBV-E group received $1.0 \mathrm{~mL}$ of deionized water and the GUA+WBV-E group received $1.0 \mathrm{~mL}$ of aqueous extract at $250 \mathrm{mg} / \mathrm{mL}$ and, then, were exposed to MV. 


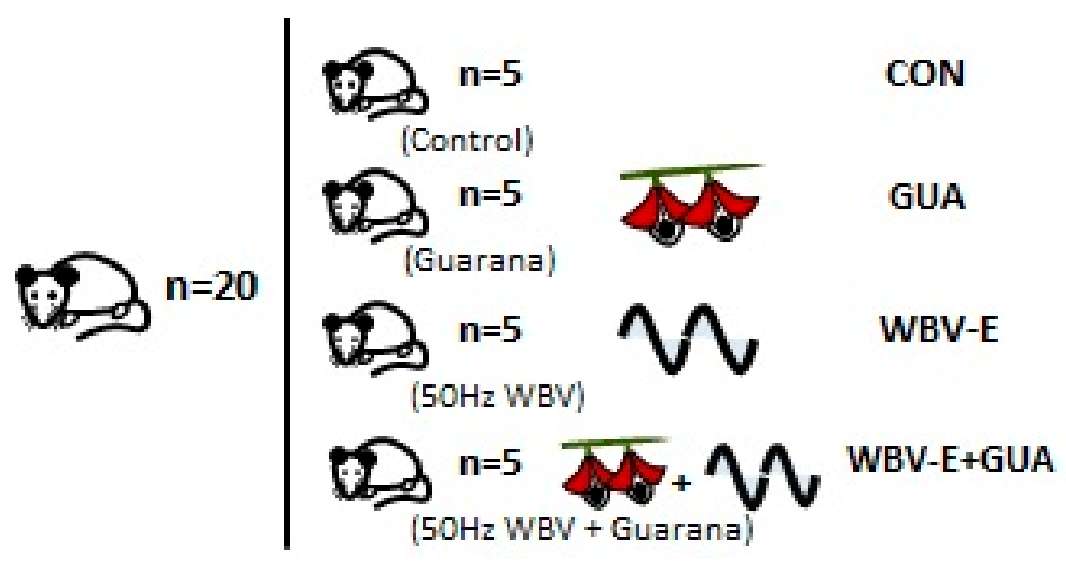

Figure 2. Experimental design for 6-weeks of treatment. Wistar rats (male, $\mathrm{n}=20$ ) were randomly divided into (CON) control; (GUA) group treated with guarana; (WBV-E) group exposed to mechanical vibration generated in platform; and (GUA + WBV-E) group treated with guarana and exposed to mechanical vibration.

WBV exercise was performed (between 7.00 and 9.00 a.m.) in four sessions of $30 \mathrm{~s}$ on a synchronous VP (Globus G-Vibe 800, Italy), which produced sinusoidal vertical $50 \mathrm{~Hz} \mathrm{MV,} 0.78 \mathrm{~mm}$ amplitude, and peak acceleration of $7.84 \mathrm{~g}$. A 1 min rest in each session, as reported by Cardoso et al. [33], was performed. The animals exposed to WBV were placed in a manmade acrylic cage fixed on the base of the VP with tape, and the animals of the CON and GUA groups that were not submitted to vibration were put close to the VP (about $20 \mathrm{~cm}$ ) (Figure 3).
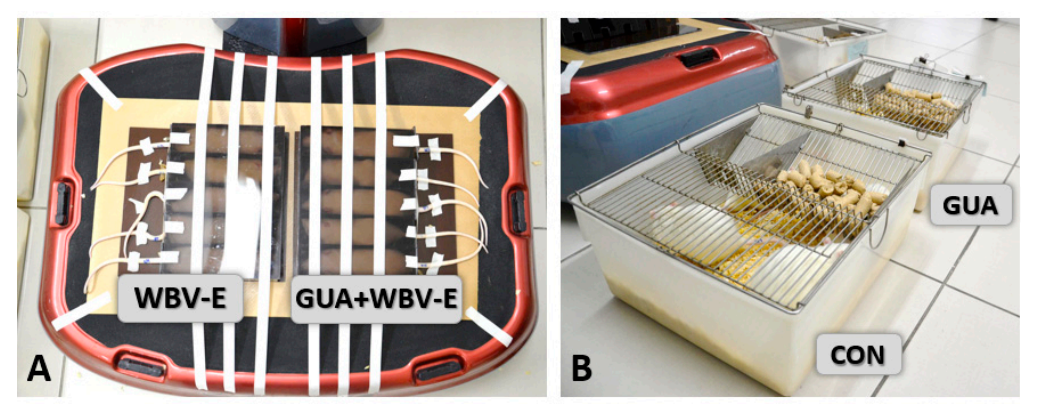

Figure 3. Rats from the groups WBV-E and GUA + WBV-E (Panel A) are placed on the base of the vibrating platform (VP) turned on. At the same time, the groups CON and GUA (Panel B) are put close (about $20 \mathrm{~cm}$ ) to the VP.

\subsection{Administration of the Radiopharmaceutical $\mathrm{Na}^{99 m} \mathrm{TcO}_{4}$}

After all the treatments (41th day), the rats were anesthetized (sodium thiopental) [36]. Afterwards (under anesthesia effect), the $\mathrm{Na}^{99} \mathrm{mcO}_{4}(1.85 \mathrm{MBq} / \mathrm{mL})$ freshly obtained from a ${ }^{99} \mathrm{Mo} /{ }^{99} \mathrm{~m} \mathrm{Tc}$ generator (Instituto de Pesquisas Energéticas e Nucleares, São Paulo, Brazil) was administrated (550 kBq/0.3 mL) via ocular plexus [31]. After $10 \mathrm{~min}$, a blood sample (by cardiac puncture) was collected for biochemical analysis of biomarkers. Then, the animals were killed $\left(\mathrm{CO}_{2}\right.$ asphyxiation) (CONCEA, 2013), and the organs (bowel, stomach, thyroid, brain, pancreas, bone, kidney, lung, liver, heart, seminal vesicle, bladder, testis, spleen, muscle, penis, and prostate) were isolated. A well counter was used to determine the radioactivity, and the percentages of the injected radioactivity per gram (\%ATI/g) in each organ calculated [28].

\subsection{Blood Biochemical Analysis}

During the biodistribution procedure, the collected blood samples were used for the measurement of the blood concentrations (urea, glucose, creatinine, triglyceride, cholesterol, high density 
lipoprotein-HDL, direct bilirubin, total bilirubin, total protein, albumin, calcium, and magnesium), as well as the concentration of some enzymes (amylase, creatine kinase-CK, lipase, aspartate aminotransferase-AST, alkaline phosphatase, and alanine aminotransferase-ALT). All the measurements were carried out with specific kits with automated equipment (COBAS INTEGRA 400 plus, Roche, Switzerland) in a clinical laboratory of the UERJ, Brazil.

\subsection{Body Mass Analysis}

The body mass of the rats was verified weekly on a balance (FILIZOLA BP6, Brazil). The percentage of the variation of mass (\%VMA) from each group was determined as the ratio between the mass of the animals at the end of each week with the mass of the animals on the first day (beginning of the experiment) multiplied by 100 .

\subsection{Food Intake Measurement}

The food intake was measured daily, $500 \mathrm{~g}$ of feed was offered daily, in each cage (group per cage). A day after this procedure (for 6-weeks), the leftover feed was determined on a digital balance (FILIZOLA BP6, São Paulo, Brazil). The food intake was calculated by the difference between $500 \mathrm{~g}$ and the leftover feed daily. Then, the quantity of feed was replenished every day to $500 \mathrm{~g}$. The mean of the total food intake during the investigation (6-weeks) was used to determine the consumption of feed per day.

\subsection{Stool Consistency Analysis}

To verify the stool consistency, a stool form scale adapted to rats, as depicted by Frederico et al. [15], was used as follows: Type 1 (hard and dry stools), Type 2 (normal), Type 3 (smooth and soft), and Type 4 (fluffy pieces with ragged edges). Three different evaluators independently analyzed the consistency of the stool, and the median of the three analyses was used as the value for stool consistency of each group.

\subsection{Statistical Analysis}

BioEstat 5.3 (Instituto Mamiraua, Pará, Brazil) was used for the data analysis. The Kruskal-Wallis test, followed by a post-test Student-Newman-Keuls, were used to analyze each parameter. Median \pm interquartile range (IQR), mean \pm standard deviation $( \pm \mathrm{SD})$, or percentage $(\%)$ were utilized to present the results. Statistical significance was accepted at $p<0.05$. To estimate the effect size, Epsilon-Squared $\left(\varepsilon^{2}\right)$ was analyzed [37]. The $\varepsilon^{2}$ considers values from zero (no relationship) to one (perfect relationship). Values about 0.5 were considered, in the current study, as a moderate relationship. The $\varepsilon^{2}$ effect sizes were measured by the formula $\varepsilon^{2}=\frac{H}{n^{2}+1 / n+1}$, where $H$ is from the Kruskal-Wallis test (the Kruskal-Wallis H-test statistic) and $n$ is the total number of observations.

\section{Results}

The effect of guarana extract and/or WBV on the biodistribution of radiopharmaceutical sodium pertechnetate was evaluated. The $\% \mathrm{ATI} / \mathrm{g}$ of the $\mathrm{Na}^{99 \mathrm{~m}} \mathrm{TcO}_{4}$ on the organs isolated from the rats submitted to the different treatments are shown in Table 1. The uptake of the radiopharmaceutical in muscle increased (i) significantly $(p<0.05)$ in the GUA group and (ii) did not increase in the GUA + WBV-E as compared with the CON group, with a moderate relationship $\left(\varepsilon^{2}=0.4979\right)$. No differences were observed in the other organs and the $\varepsilon^{2}$ was small (0.0177 to 0.4280). Although without significant difference, the uptake of sodium pertechnetate in the prostate increased in the GUA, WBV-E, and GUA+WBV-E. 
Table 1. \%ATI/g of the $\mathrm{Na}^{99 m} \mathrm{TcO}_{4}$ from organs isolated from the rats submitted to some interventions.

\begin{tabular}{ccccccc}
\hline ORGANS & CON & GUA & WBV-E & GUA+WBV-E & $p$ & $\varepsilon^{2}$ \\
\hline Thyroid & $7.82 \pm 2.75$ & $7.76 \pm 2.30$ & $7.81 \pm 1.25$ & $7.91 \pm 0.54$ & 0.8142 & 0.0631 \\
Stomach & $5.16 \pm 1.54$ & $5.69 \pm 2.05$ & $5.93 \pm 1.46$ & $8.55 \pm 1.43$ & 0.1134 & 0.3727 \\
Bowel & $1.15 \pm 0.28$ & $1.65 \pm 0.21$ & $1.22 \pm 0.22$ & $1.39 \pm 0.27$ & 0.1120 & 0.4280 \\
Kidney & $1.57 \pm 0.11$ & $1.60 \pm 0.23$ & $1.66 \pm 0.38$ & $1.60 \pm 0.14$ & 0.5756 & 0.1103 \\
Liver & $1.86 \pm 0.45$ & $2.45 \pm 0.63$ & $2.33 \pm 0.42$ & $2.42 \pm 0.43$ & 0.4078 & 0.1525 \\
Pancreas & $1.30 \pm 0.16$ & $0.85 \pm 0.34$ & $1.31 \pm 0.25$ & $1.29 \pm 0.40$ & 0.2268 & 0.2554 \\
Brain & $0.07 \pm 0.04$ & $0.10 \pm 0.02$ & $0.09 \pm 0.03$ & $0.10 \pm 0.01$ & 0.8185 & 0.0546 \\
Bone & $0.41 \pm 0.19$ & $0.69 \pm 0.20$ & $0.51 \pm 0.10$ & $0.66 \pm 0.18$ & 0.1718 & 0.2632 \\
Lung & $1.85 \pm 0.64$ & $1.95 \pm 0.29$ & $1.81 \pm 0.53$ & $2.01 \pm 1.38$ & 0.9529 & 0.0177 \\
Heart & $1.01 \pm 0.73$ & $0.92 \pm 0.42$ & $1.02 \pm 0.18$ & $1.14 \pm 0.39$ & 0.7160 & 0.0797 \\
Spleen & $1.00 \pm 0.09$ & $1.17 \pm 0.18$ & $1.15 \pm 0.26$ & $1.06 \pm 0.10$ & 0.5052 & 0.1299 \\
Muscle & $0.27 \pm 0.11$ & $0.43 \pm 0.07 *$ & $0.28 \pm 0.06$ & $0.35 \pm 0.02$ & 0.0298 & 0.4979 \\
Penis & $1.63 \pm 0.26$ & $1.79 \pm 0.36$ & $1.69 \pm 0.21$ & $1.73 \pm 0.39$ & 0.7487 & 0.0641 \\
Prostate & $0.53 \pm 0.14$ & $0.90 \pm 0.23$ & $0.77 \pm 0.29$ & $0.93 \pm 0.21$ & 0.0983 & 0.3311 \\
Seminal vesicle & $0.54 \pm 0.21$ & $0.54 \pm 0.16$ & $0.44 \pm 0.14$ & $0.54 \pm 0.19$ & 0.7489 & 0.0641 \\
Bladder & $1.28 \pm 0.15$ & $1.68 \pm 0.46$ & $1.32 \pm 0.34$ & $1.30 \pm 0.55$ & 0.4659 & 0.1963 \\
Testis & $0.55 \pm 0.17$ & $0.51 \pm 0.19$ & $0.48 \pm 0.04$ & $0.56 \pm 0.16$ & 0.6125 & 0.0953 \\
Blood & $2.58 \pm 0.61$ & $2.52 \pm 0.35$ & $2.79 \pm 1.66$ & $2.95 \pm 0.88$ & 0.7817 & 0.0721 \\
\hline
\end{tabular}

$\mathrm{CON}$, control; GUA, group treated with guarana; WBV-E, group exposed to mechanical vibration generated in vibrating platform; GUA + WBV-E, group treated with guarana and exposed to mechanical vibration. Values presented in means $\pm \mathrm{SD}$ and $\varepsilon^{2}$, epsilon squared. Adjusted $p$ values (Student-Newman-Keuls correction) were considered significant at $p<0.05$. ${ }^{*} p<0.01$ compared to CON and WBV-E groups.

The effect of guarana extract and/or WBV on the concentration of blood biomarkers are shown in Table 2. After 6-weeks of all interventions, there was an increase in the calcium levels $(p>0.05)$ of the animals submitted to WBV (WBV-E and GUA + WBV-E) as compared with the animals in the GUA group. No differences were found in the other biomarkers. The $\varepsilon^{2}$ revealed values from 0.0291 to 0.3995 (small relationship).

Table 2. Blood biomarkers concentrations of the animals submitted to some interventions.

\begin{tabular}{ccccccc}
\hline Biomarkers & CON & GUA & WBV-E & GUA+WBV-E & $p$ & $\varepsilon^{2}$ \\
\hline Albumin $(\mathrm{g} / \mathrm{L})$ & $34.7 \pm 1.0$ & $34.2 \pm 1.3$ & $36.2 \pm 2.5$ & $37.4 \pm 2.3$ & 0.1138 & 0.3308 \\
Calcium $(\mathrm{mmol} / \mathrm{L})$ & $2.38 \pm 0.07$ & $2.36 \pm 0.02$ & $2.52 \pm 0.20^{*}$ & $2.48 \pm 0.08^{*}$ & 0.0449 & 0.4475 \\
Creatinine $(\mu \mathrm{mol} / \mathrm{L})$ & $39.78 \pm 8.84$ & $37.13 \pm 3.54$ & $40.66 \pm 7.96$ & $37.13 \pm 3.54$ & 0.83241 & 0.0484 \\
Cholesterol $(\mathrm{mmol} / \mathrm{L})$ & $1.07 \pm 0.15$ & $1.21 \pm 0.21$ & $1.07 \pm 0.23$ & $1.16 \pm 0.13$ & 0.5365 & 0.1209 \\
Glucose $(\mathrm{mmol} / \mathrm{L})$ & $6.22 \pm 0.45$ & $5.69 \pm 0.44$ & $5.76 \pm 0.18$ & $5.85 \pm 0.94$ & 0.4270 & 0.1853 \\
HDL $(\mathrm{mmol} / \mathrm{L})$ & $1.09 \pm 0.07$ & $1.16 \pm 0.15$ & $1.07 \pm 0.17$ & $1.13 \pm 0.11$ & 0.7040 & 0.0781 \\
Magnesium $(\mathrm{mmol} / \mathrm{L})$ & $1.10 \pm 0.14$ & $1.00 \pm 0.06$ & $1.27 \pm 0.36$ & $1.17 \pm 0.11$ & 0.0661 & 0.3995 \\
Direct Bilirubin $(\mu \mathrm{mol} / \mathrm{L})$ & $0.34 \pm 0.17$ & $0.51 \pm 0.17$ & $0.34 \pm 0.17$ & $0.34 \pm 0.17$ & 0.2657 & 0.2330 \\
Total Bilirubin $(\mu \mathrm{mol} / \mathrm{L})$ & $0.86 \pm 0.51$ & $0.68 \pm 0.51$ & $0.51 \pm 0.17$ & $0.68 \pm 0.34$ & 0.9386 & 0.0291 \\
Total Protein $(\mathrm{g} / \mathrm{L})$ & $57.7 \pm 2.5$ & $59.0 \pm 1.9$ & $62.2 \pm 4.0$ & $61.8 \pm 3.8$ & 0.1185 & 0.3257 \\
Triglyceride $(\mathrm{mmol} / \mathrm{L})$ & $0.47 \pm 0.26$ & $0.52 \pm 0.16$ & $0.42 \pm 0.14$ & $0.38 \pm 0.11$ & 0.6177 & 0.0993 \\
Urea $(\mathrm{mmol} / \mathrm{L})$ & $7.84 \pm 1.01$ & $7.07 \pm 0.32$ & $7.47 \pm 0.42$ & $7.57 \pm 0.53$ & 0.3153 & 0.1968 \\
\hline CON, control; GUA, group treated with guarana; WBV-E, group exposed to mechanical vibration generated in \\
platform; GUA + WBV-E, group treated with guarana and exposed to mechanical vibration. Values are presented in \\
means \pm SD and $\varepsilon^{2}$, epsilon squared. * $p<0.05$ compared with GUA. & & &
\end{tabular}

The evaluation of the effect of guarana extract and/or WBV on the enzymatic activities after 6-weeks revealed no differences in the blood concentration of the enzymes evaluated amongst the rats submitted to the always treatments (Table 3 ). The $\varepsilon^{2}$ indicated no relationship. 
Table 3. Enzymes concentrations in animals submitted to some interventions.

\begin{tabular}{ccccccc}
\hline Enzymes & CON & GUA & WBV-E & GUA+WBV-E & $p$ & $\varepsilon^{2}$ \\
\hline Amylase $(\mu$ Kat $/ \mathrm{L})$ & $0.79 \pm 0.08$ & $0.77 \pm 0.14$ & $00.75 \pm 0.10$ & $0.80 \pm 0.06$ & 0.8384 & 0.0470 \\
AST $(\mu$ Kat $/ \mathrm{L})$ & $2.20 \pm 0.25$ & $2.45 \pm 0.21$ & $2.30 \pm 0.49$ & $2.38 \pm 0.30$ & 0.5325 & 0.1465 \\
ALT $(\mu$ Kat/L) & $1.02 \pm 0.12$ & $1.13 \pm 0.21$ & $1.12 \pm 0.10$ & $1.21 \pm 0.10$ & 0.3990 & 0.1640 \\
ALP $(\mu$ Kat $/ \mathrm{L})$ & $2.20 \pm 0.30$ & $1.92 \pm 0.29$ & $2.16 \pm 0.27$ & $2.30 \pm 0.21$ & 0.3064 & 0.2007 \\
Lipase $(\mu$ Kat/L) & $0.11 \pm 0.01$ & $0.11 \pm 0.00$ & $0.11 \pm 0.01$ & $0.12 \pm 0.01$ & 0.6838 & 0.0830 \\
CK $(\mu$ Kat/L) & $31.97 \pm 1.03$ & $31.56 \pm 6.74$ & $26.73 \pm 4.74$ & $28.58 \pm 7.41$ & 0.6170 & 0.0411 \\
\hline
\end{tabular}

$\mu \mathrm{Kat} / \mathrm{L}$, microkatal; CON, control; GUA, group treated with guarana; WBV-E, group exposed to mechanical vibration generated in platform; GUA + WBV-E, group treated with guarana and exposed to mechanical vibration. Values are presented in means $\pm \mathrm{SD}$ and $\varepsilon^{2}$, epsilon squared.

The study of the effect of guarana extract and/or WBV on the food intake and body mass for 6-weeks of intervention, revealed that the animals treated with guarana and WBV (the GUA + WBV-E group) had a significant decrease $(p<0.05)$ in food intake as compared with the CON group. However, the animals treated with guarana (the GUA group) had no statistical decrease in food intake as compared with the CON group but had a feed consumption higher than that of the GUA + WBV-E group. The animals treated with only WBV-E (the WBV-E group) had a statistical increase in food intake as compared with the CON group (Figure 4). The $\varepsilon^{2}$ (not shown in the figure) was 0.1216, indicating a small relationship.

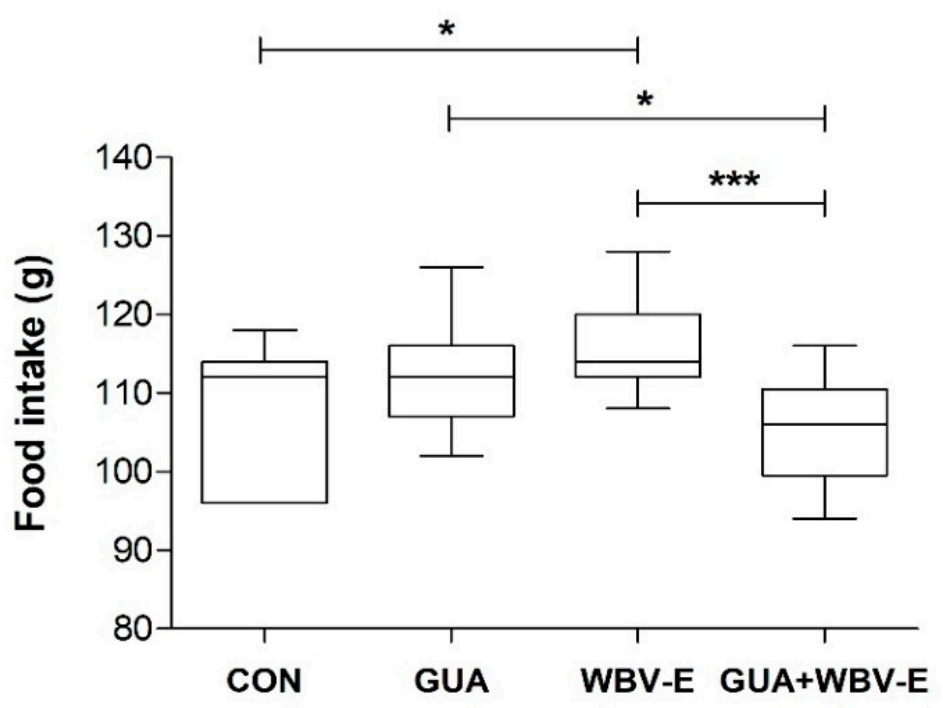

Figure 4. Food intake (g) of animals exposed to different treatments (CON, control; GUA, group treated with guarana; WBV-E, group exposed to mechanical vibration generated in platform, GUA + WBV-E, group treated with guarana and exposed to mechanical vibration). Adjusted $p$ values (Kruskal-Wallis) were considered significant at $*<0.05$, and ${ }^{* * *} p<0.001$.

Table 4 shows that the body mass of animals from all groups increased (about 20\%) during the period of the interventions but not significantly $(p<0.05)$ among the groups. The values of $\varepsilon^{2}$ varied from 0.1294 to 0.3657 (small relationship). 
Table 4. Body mass (\%) of the animals submitted to some interventions.

\begin{tabular}{ccccccc}
\hline WEEK & CON & GUA & WBV-E & GUA+WBV-E & $p$ & $\varepsilon^{2}$ \\
\hline 0 & $100.00 \pm 8.89$ & $100.00 \pm 8.21$ & $100.00 \pm 11.7$ & $100.00 \pm 2.10$ & 0.4828 & 0.1294 \\
1 & $103.90 \pm 7.20$ & $103.27 \pm 7.67$ & $105.29 \pm 9.54$ & $105.12 \pm 3.80$ & 0.3452 & 0.1746 \\
2 & $109.00 \pm 5.29$ & $107.00 \pm 7.24$ & $113.40 \pm 6.38$ & $108.92 \pm 3.42$ & 0.0839 & 0.3501 \\
3 & $112.31 \pm 5.78$ & $111.99 \pm 7.04$ & $116.77 \pm 5.33$ & $113.55 \pm 3.63$ & 0.1014 & 0.3273 \\
4 & $115.31 \pm 6.34$ & $115.42 \pm 7.82$ & $120.38 \pm 4.41$ & $116.94 \pm 4.29$ & 0.1101 & 0.3174 \\
5 & $118.61 \pm 6.04$ & $119.15 \pm 4.94$ & $123.27 \pm 4.45$ & $121.57 \pm 3.88$ & 0.0736 & 0.3657 \\
\hline
\end{tabular}

$\mathrm{CON}$, control; GUA, group treated with guarana; WBV-E, group exposed to mechanical vibration generated in platform; GUA + WBV-E, group treated with guarana and exposed to mechanical vibration. Values are presented in percentage (\%) as the means $\pm \mathrm{SD}$ and $\varepsilon^{2}$, epsilon squared.

The effect of guarana extract and/or WBV on stool consistency was evaluated for 6-weeks of treatments. The stool consistencies of the rats are shown in Table 5. The consistency of the stool among the animals that received guarana (GUA and GUA+WBV-E groups, Type 4$)$ was altered $(p<0.05)$ as compared with the animals that did not receive guarana (CON and WBV-E, type 2). The $\varepsilon^{2}$ was 0.6016 (a moderate relationship).

Table 5. Stool consistency of animals submitted to some interventions.

\begin{tabular}{|c|c|c|c|c|c|c|}
\hline Day & $\mathrm{CON}$ & GUA & WBV-E & GUA+WBV-E & $p$ & $\varepsilon^{2}$ \\
\hline $1-10$ & $2.00 \pm 0.00$ & $4.00 \pm 0.00^{* * *}$ & $3.00 \pm 1.00^{\#}$ & $4.00 \pm 0.75^{* *}$ & 0.0005 & 0.4566 \\
\hline $11-20$ & $2.00 \pm 0.00$ & $4.00 \pm 0.00 * * *$ & $2.00 \pm 0.00^{\# \#}$ & $4.00 \pm 0.00^{* *+}$ & $<0.0001$ & 0.6272 \\
\hline $21-30$ & $2.00 \pm 0.00$ & $4.00 \pm 0.00 * * *$ & $2.00 \pm 0.00^{\# \#}$ & $4.00 \pm 1.00^{* *+}$ & $<0.0001$ & 0.6527 \\
\hline $31-40$ & $2.00 \pm 0.00$ & $4.00 \pm 0.75 * * *$ & $2.00 \pm 0.00$ \#\#\# & $3.00 \pm 1.00^{* * *++}$ & $<0.0001$ & 0.7726 \\
\hline Total (1-40) & $2.00 \pm 0.00$ & $4.00 \pm 0.25^{* * *}$ & $2.00 \pm 0.00$ \#\#\# & $4.00 \pm 1.00^{* * *+++}$ & $<0.0001$ & 0.6016 \\
\hline
\end{tabular}

\section{Discussion}

Studies that have assessed the effects of natural products in association with WBV exercise in animals $[14,15,32]$ stimulated the motivation for this current investigation. In this study, biological responses of treatment with guarana extract alone or combined with WBV exercise have been verified based on the biodistribution of the $\mathrm{Na}^{99 \mathrm{~m}} \mathrm{TcO}_{4}$, on the concentration of selected blood biomarkers, body mass, food intake, and stool consistency, in Wistar rats.

In general, the distribution pattern of a radiopharmaceutical in the body depends on the physiological conditions of an organ or tissue [32]. Previously, Pereira et al. [37] demonstrated, in rats, that exposure to $20 \mathrm{~Hz}$ of WBV could alter the uptake of a radiopharmaceutical. Frederico et al. [32] showed that the association of coriander (natural product) and WBV $(12 \mathrm{~Hz})$ increased the uptake of $\mathrm{Na}^{99} \mathrm{TcO}_{4}$ in the spleen. The determination of the $\mathrm{Na}^{99}{ }^{99} \mathrm{TcO}_{4}$ uptake in organs (Table 1) made it possible to check the effects of different treatments in organs. Guarana treatment increased the uptake of $\mathrm{Na}^{99 \mathrm{~m}} \mathrm{TcO}_{4}$ in muscle. This increase could possibly be due to the caffeine, a component of guarana [4]. According to Behrens et al. [38], the ingestion of caffeine induced increases in the voluntary activation and strength of the quadriceps muscle during isometric, concentric, and eccentric contractions. Furthermore, in general, the interventions did not promote modifications at different levels (molecular or cellular) in the several organs that were capable of interfering in the uptake of the radiopharmaceutical $\mathrm{Na}^{99} \mathrm{TcO}_{4}$. The addition of WBV-E to the GUA treatment did not alter the uptake of $\mathrm{Na}^{99 m} \mathrm{TcO}_{4}$ as compared with the CON. In the current study, the intervention with WBV-E only or associated with guarana did not modify the uptake of the radiopharmaceutical, 
however, Amin et al. [39] described, in humans, the influence of WBV on bone scintigraphy using ${ }^{99 \mathrm{~m}}$ Tc-methylene diphosphonate.

For a period of 6-weeks (40 days), the interventions with WBV $(50 \mathrm{~Hz})$, the WBV-E and GUA + WBV-E groups, had increased calcium levels as compared with the GUA group (Table 2). It is well-known that the calcium level in blood is mainly controlled by the parathyroid glands and, when the body needs calcium, the parathyroid glands secrete a hormone called parathyroid hormone (PTH) $[40,41]$. Therefore, it is possible to infer that WBV exercises promote an osteogenic effect that causes the PTH to signal the bone to release more calcium, which explains the increased calcium levels in the blood of these animals, and offers insight into on how bone construction mechanisms behave while receiving the vibration stimuli [41,42].

Considering the food intake for the period of 6-weeks, an increase of food intake was observed in the WBV-E group. This finding corroborates with Frederico et al. [15] and Cardoso et al. [33] who also observed, for 6-weeks, a significant increase of food intake in rats exposed to WBV at $50 \mathrm{~Hz}$, as well as an increase in a GUA group. Our finding is in agreement with Dorneles et al. [43] who observed, after 30 days of treatment, that the daily administration of 200 and $400 \mathrm{mg}$ of guarana increased appetite. In contrast, they observed a decrease in food intake of the rats exposed to WBV exercise in combination with guarana (the GUA + WBV-E group), notably, an interesting finding. It was expected that food intake would increase in the concomitant treatment, as noted in the results of both agents separately as compared with the CON group (Figure 4). Other than this decrease, no significant change in body mass of the GUA + WBV-E group was observed. Some studies have shown that guarana can slow and inhibit the production of fat cells to help decrease body fat $[43,44]$.

With respect to the body mass of the animals (Table 4), an increase in the percentage was shown over the weeks, but no statistical difference was observed among the groups. Therefore, the body mass and food intake outcomes observed in this investigation can be highlighted as interesting findings. In healthy rats, the food intake increase did not have a direct influence on the body mass increase. In similar conditions, previous works $[15,33]$ have shown (either in animals that only received the natural product or WBV, or in association) that the food intake increased without modification of the body mass. These findings could be explained by the specific increase of ATP turnover in intact or skinned single fiber promoted by the applied vibration [45]. Additionally, even by the changes in lipid metabolism induced by consumption of guarana [46], which could require an increase in the energetic metabolism, contributing to control of body mass gain by the animal.

The stool consistency (Table 4) was altered in rats that consumed guarana, which was classified as Type 4 (fluffy pieces with ragged edges), unlike the animals that did not consume the extract (Type 2, normal). Oliveira [47] reported that one of the main causes of diarrhea in runners is caffeine, one of the main chemical constituents of guarana. Moreover, Lee et al. [48] reported that, at $12 \mathrm{~Hz}$ frequency, WBV influences the pelvic floor muscles. Furthermore, Frederico et al. [15] also observed a modification in stool consistency of animals that consumed coriander for 6-weeks.

This investigation has some limiting factors, such as the number of animals per group. Nonetheless, the criteria previously described by de Boo and Hendriksen [49] were followed. Furthermore, a special commercial cage was not used to separate the stools. In addition, the blood concentration of biomarkers linked to the stress was not considered in this study.

\section{Conclusions}

Despite the limitations, and although the food intake decreased with the association of guarana and WBV exercise (GUA + WBV-E), it is possible to conclude that body mass did not changed. In addition, guarana extract promoted effects on muscle as compared with the control group, and the increase in the uptake of $\mathrm{Na}^{99 \mathrm{~m}} \mathrm{TcO}_{4}$ justifies the alterations previously reported for natural products on the uptake of sodium pertechnetate in selected organs.

Guarana also promoted modification in stool consistency and did not alter the body mass of the rats, reinforcing guarana as a functional food. This dataset and the knowledge of the association of 
guarana with WBV can give greater reliability concerning the effects of guarana in healthy animals, opening pathways to further investigations that involve this type of treatment in experimental models for diabetes, cancer, and Alzheimer disease.

This dataset and knowledge of the association of guarana with vibration give greater reliability concerning the effects of guarana, as well as give a reference for further studies.

Author Contributions: Conceptualization, A.L.B.D.C., É.H.F.F.F., N.R.A. and M.B.-F.; Data curation, É.H.F.F.F., C.A.S.G. and D.d.C.d.S.-C.; Formal analysis, D.d.C.d.S.-C. and L.L.P.-D.; Investigation, A.L.B.D.C. and N.R.A.; Methodology, A.L.B.D.C., É.H.F.F.F., C.A.S.G., A.R.-S., E.d.O.G.-A., A.F.S., M.C.M.-F., L.F.F.-S., T.E.-S., D.E.-S., R.G.M., D.d.C.d.S.-C. and L.L.P.-D.; Project administration, A.L.B.D.C. and N.R.A.; Resources, M.B.-F.; Software, D.d.C.d.S.-C. and N.R.A.; Supervision, R.T. and M.B.-F.; Validation, R.T.; Writing-original draft, A.L.B.D.C.; Writing-review \& editing, A.L.B.D.C., R.T. and M.B.-F. All authors have read and agreed to the published version of the manuscript.

Funding: Conselho Nacional de Pesquisa e Desenvolvimento Científico e Tecnológico (CNPq), Coordenação de Aperfeiçoamento de Pessoal de Nível Superior-Brazil (CAPES)-Finance Code 001, and Fundação de Amparo à pesquisa do Estado do Rio de Janeiro (FAPERJ) have supported this investigation.

Conflicts of Interest: The authors declare no conflict of interest.

\section{References}

1. Alviano, D.S.; Alviano, C.S. Plant extracts: Search for new alternatives to treat microbial diseases. Curr. Pharm. Biotechnol. 2009, 10, 106-121. [CrossRef] [PubMed]

2. Khan, U.A.; Rahman, H.; Niaz, Z.; Qasim, M.; Khan, J.; Tayyaba Rehman, B. Antibacterial activity of some medicinal plants against selected human pathogenic bacteria. Eur. J. Microbiol. Immunol. 2013, 3, 272-274. [CrossRef] [PubMed]

3. Henman, A.R. Guaraná (Paullinia cupana var. sorbilis): Ecological and social perspectives on an economic plant of the central Amazon basin. J. Ethnopharmacol. 1982, 6, 311-338. [CrossRef]

4. Schimpl, F.C.; da Silva, J.F.; Gonçalves, J.F.; Mazzafera, P. Guarana: Revisiting a highly caffeinated plant from the Amazon. J. Ethnopharmacol. 2013, 150, 14-31. [CrossRef]

5. Hertz, E.; Cadoná, F.C.; Machado, A.K.; Azzolin, V.; Holmrich, S.; Assmann, C.; Ledur, P.; Ribeiro, E.E.; Souza Filho, O.C.; Mânica-Cattani, M.F.; et al. Effect of Paullinia cupana on MCF-7 breast cancer cell response to chemotherapeutic drugs. Mol. Clin. Oncol. 2015, 3, 37-43. [CrossRef]

6. Carvalho, L.V.D.N.; Cordeiro, M.F.; Sampaio, M.C.P.D.; de Mello, G.S.V.; da Costa, V.D.C.M.; Marques, L.L.M.; Klein, T.; de Mello, J.C.P.; Cavalcanti, I.M.F.; Pitta, I.R.; et al. Evaluation of antibacterial, antineoplastic, and immunomodulatory activity of Paullinia cupana seeds crude extract and ethyl-acetate fraction. Evid. Based Complement. Altern. Med. 2016, 2016, 1203274. [CrossRef]

7. Bulku, E.; Zinkovsky, D.; Patel, P.; Javia, V.; Lahoti, T.; Khodos, I.; Stohs, S.J.; Ray, S.D. A novel dietary supplement containing multiple phytochemicals and vitamins elevates hepatorenal and cardiac antioxidant enzymes in the absence of significant serum chemistry and genomic changes. Oxidative Med. Cell. Longevity 2010, 3, 129-144. [CrossRef]

8. Krewer Cda, C.; Ribeiro, E.E.; Ribeiro, E.A.; Moresco, R.N.; da Rocha, M.I.; Montagner, G.F.; Machado, M.M.; Viegas, K.; Brito, E.; da Cruz, I.B. Habitual intake of guaraná and metabolic morbidities: An epidemiological study of an elderly Amazonian population. Phytother. Res. 2011, 25, 1367-1374. [CrossRef]

9. Andersen, T.; Fogh, J. Weight loss and delayed gastric emptying following a South American herbal preparation in overweight patients. J. Hum. Nutr. Diet. 2001, 14, 243-250. [CrossRef]

10. Audi, E.A.; de Mello, J.C.P. Efeito antidepressivo do extrato da droga vegetal guaraná (Paullinia cupana var. sorbilis (Martius) Ducke). Fundação Universidade Estadual de Maringá BR Patent\# PI00066389 Cl. Int. A61P 2000, 25, A61K.

11. Rangel, M.P.; Mello, J.C.P.; Audi, E.A. Evaluation of neurotransmitters involved in the anxiolytic and panicolytic effect of the aqueous fraction of Paullinia cupana (Guaraná) in elevated T maze. Revista Brasileira de Farmacognosia 2013, 23, 358-365. [CrossRef] 
12. Chen, G.X.; Zheng, S.; Qin, S.; Zhong, Z.M.; Wu, X.H.; Huang, Z.P.; Li, W.; Ding, R.T.; Yu, H.; Chen, J.T. Effect of low-magnitude whole-body vibration combined with alendronate in ovariectomized rats: A random controlled osteoporosis prevention study. PLoS ONE 2014, 9, e96181. [CrossRef] [PubMed]

13. Stuermer, E.K.; Komrakova, M.; Sehmisch, S.; Tezval, M.; Dullin, C.; Schaefer, N.; Hallecker, J.; Stuermer, K.M. Whole body vibration during fracture healing intensifies the effects of estradiol and raloxifene in estrogen-deficient rats. Bone 2014, 64, 187-194. [CrossRef] [PubMed]

14. Naghii, M.R.; Darvishi, P.; Ebrahimpour, Y.; Ghanizadeh, G.; Mofid, M.; Hedayati, M.; Asgari, A.R. Effect of combination therapy of fatty acids, calcium, vitamin D and boron with regular physical activity on cardiovascular risk factors in rat. J. Oleo Sci. 2012, 61, 103-111. [CrossRef] [PubMed]

15. Frederico, E.H.F.F.; Cardoso, A.L.B.D.; Guimarães, C.A.S.; Almeida, L.P.; Neves, R.F.; Sá-Caputo, D.C.; Moreira-Marconi, E.; Dionello, C.F.; Morel, D.S.; Paineiras-Domingos, L.L.; et al. Whole body vibration exercise combined with an extract of Coriandrum sativum modify some biochemical/physiological parameters in rats. Biosci. Rep. 2017, 37. [CrossRef]

16. Coza, A.; Nigg, B.M.; Dunn, J.F. Effects of vibrations on gastrocnemius medialis tissue oxygenation. Med. Sci. Sports Exerc. 2011, 43, 509-515. [CrossRef]

17. Rauch, F.; Sievanen, H.; Boonen, S.; Cardinale, M.; Degens, H.; Felsenberg, D.; Roth, J.; Schoenau, E.; Verschueren, S.; Rittweger, J. Reporting whole-body vibration intervention studies: Recommendations of the International Society of Musculoskeletal and Neuronal Interactions. J. Musculoskelet. Neuronal Interact. 2010, 10, 193-198.

18. Rittweger, J. Vibration as an exercise modality: How it may work, and what its potential might be. Eur. J. Appl. Physiol. 2010, 108, 877-904. [CrossRef]

19. Huh, J.Y.; Mougios, V.; Skraparlis, A.; Kabasakalis, A.; Mantzoros, C.S. Irisin in response to acute and chronic whole-body vibration exercise in humans. Metabolism 2014, 63, 918-921. [CrossRef]

20. Goto, K.; Takamatsu, K. Hormone and lipolytic responses to whole body vibration in young men. Jpn. J. Physiol. 2005, 55, 279-284. [CrossRef]

21. Di Giminiani, R.; Fabiani, L.; Baldini, G.; Cardelli, G.; Giovannelli, A.; Tihanyi, J. Hormonal and neuromuscular responses to mechanical vibration applied to upper extremity muscles. PLoS ONE 2014, 9, e111521. [CrossRef] [PubMed]

22. Erceg, D.N.; Anderson, L.J.; Nickles, C.M.; Lane, C.J.; Weigensberg, M.J.; Schroeder, E.T. Changes in bone biomarkers, BMC, and insulin resistance following a 10-week whole body vibration exercise program in overweight Latino boys. Int. J. Med. Sci. 2015, 12, 494. [CrossRef] [PubMed]

23. Verschueren, S.M.; Roelants, M.; Delecluse, C.; Swinnen, C.; Vanderschueren, D.; Boonen, S. Effect of 6-month whole body vibration training on hip density, muscle strength, and postural control in postmenopausal women: A randomized controlled pilot study. J. Bone Miner. Res. 2004, 19, 352-359. [CrossRef] [PubMed]

24. Park, S.Y.; Son, W.M.; Kwon, O.S. Effects of whole body vibration training on body composition, skeletal muscle strength, and cardiovascular health. J. Exerc. Rehabil. 2015, 11, 289. [CrossRef]

25. Tseng, S.Y.; Hsu, P.S.; Lai, C.L.; Liao, W.C.; Lee, M.C.; Wang, C.H. Effect of two frequencies of whole-body vibration training on balance and flexibility of the elderly: A randomized controlled trial. Am. J. Phys. Med. Rehabil. 2016, 95, 730-737. [CrossRef]

26. Regterschot, G.R.H.; Van Heuvelen, M.J.G.; Zeinstra, E.B.; Fuermaier, A.B.M.; Tucha, L.; Koerts, J.; Tucha, O.; Van Der Zee, E.A. Whole body vibration improves cognition in healthy young adults. PLoS ONE 2014, 9, e100506. [CrossRef]

27. Hladik, W.B., III; Nigg, K.K.; Rhodes, B.A. Drug-induced changes in the biologic distribution of radiopharmaceuticals. In Seminars in Nuclear Medicine; WB Saunders: Philadelphia, PA, USA, 1982; Volume 12, pp. 184-218.

28. Góes, V.C.; Neves, R.H.; Arnóbio, A.; Bernardo-Filho, M.; Machado-Silva, J.R. Streptozotocin (STZ) and schistosomiasis mansoni change the biodistribution of radiopharmaceutical sodium 99mTc-pertechnetate in mice. Nuclear Med. Biol. 2016, 43, 581-586. [CrossRef]

29. El-Shabrawi, M.H.; Omran, S.; Wageeh, S.; Isa, M.; Okasha, S.; Mohsen, N.A.; El-Karaksy, H.M. 99mTechnetium-macroaggregated albumin perfusion lung scan versus contrast enhanced echocardiography in the diagnosis of the hepatopulmonary syndrome in children with chronic liver disease. Eur. J. Gastroenterol. Hepatol. 2010, 22, 1006-1012. [CrossRef] 
30. Selivanova, S.V.; Lavallée, É.; Senta, H.; Caouette, L.; Mcewan, A.J.; Guérin, B.; Turcotte, É. Clinical Trial with Sodium 99mTc-Pertechnetate Produced by a Medium-Energy Cyclotron: Biodistribution and Safety Assessment in Patients with Abnormal Thyroid Function. J. Nucl. Med. 2017, 58, 791-798. [CrossRef]

31. Holanda, C.M.D.C.X.; Barbosa, D.A.; Demeda, V.F.; Bandeira, F.T.M.; Medeiros, H.C.S.D.; Pereira, K.R.S.G.; Medeiros, A.C. Influence of Annona muricata (soursop) on biodistribution of radiopharmaceuticals in rats. Acta Cirurgica Brasileira 2014, 29, 145-150. [CrossRef]

32. Frederico, E.H.F.F.; Carmo, F.S.; Arnóbio, A.; Guedes, S.S.V.; Sá-Caputo, D.C.; Bernardo, L.C.; Bernardo-Filho, M. Does the whole body vibration alter the effect of a Coriandrum sativum extract on the biodistribution of the radiopharmaceutical technetium-99m sodium pertechnetate and some biomarkers in Wistar rats? Int. J. Pharm. Sci. Res. 2014, 5, 3529.

33. Cardoso, A.L.B.D.; Frederico, É.H.F.F.; Guimarães, C.A.S.; Almeida, L.P.; de Figueiredo Neves, R.; de Sá-Caputo, D.; Moreira-Marconi, E.; Dionello, C.F.; Morel, D.S.; Paineiras-Domingos, L.L.; et al. Chenopodium ambrosioides associated with whole body vibration exercises alters the feed intake in Wistar rats. Biosci. Rep. 2017, 37, BSR20170846. [CrossRef] [PubMed]

34. Lima, N.; Teixeira, L.; Gambero, A.; Ribeiro, M. Guarana (Paullinia cupana) stimulates mitochondrial biogenesis in mice fed high-fat diet. Nutrients 2018, 10, 165. [CrossRef] [PubMed]

35. Celik, F.; Gocmez, C.; Bozkurt, M.; Kaplan, I.; Kamasak, K.; Akil, E.; Uzar, E. Neuroprotective effects of carvacrol and pomegranate against methotrexate-induced toxicity in rats. Eur. Rev. Med. Pharm. Sci. 2013, 17, 2988-2993.

36. Otero-Losada, M.; González, J.; Müller, A.; Ottaviano, G.; Cao, G.; Azzato, F.; Milei, J. Exercise ameliorates endocrine pancreas damage induced by chronic cola drinking in rats. PLoS ONE 2016, 11, e0155630. [CrossRef]

37. Tomczak, M.; Tomczak, E. The need to report effect size estimates revisited. An overview of some recommended measures of effect size. Trends Sport Sci. 2014, 21, 19-25.

38. Pereira, M.O.; Pinto, N.S.; Monteiro, M.O.; Santos-Filho, S.D.; Carmo, F.S.; Diniz, C.L.; Marin, P.J.; Bernardo-Filho, M. Influence of Whole-body vibration on biodistribution of the radiopharmaceutical [99mTc] methylene diphosphonate in Wistar rats. Int. J. Radiat. Biol. 2013, 89, 668-672. [CrossRef]

39. Behrens, M.; Mau-Moeller, A.; Weippert, M.; Fuhrmann, J.; Wegner, K.; Skripitz, R.; Bruhn, S. Caffeine-induced increase in voluntary activation and strength of the quadriceps muscle during isometric, concentric and eccentric contractions. Sci. Rep. 2015, 5, 10209. [CrossRef]

40. Amin, A.; El-Kareem, M.A.; Yahia, A.B. Influence of low grade exercise on skeletal scintigraphy using Tc-99m methylene diphosphonate. Nuclear Med. Rev. Cent. East. Eur. 2015, 18, 61-64. [CrossRef]

41. Gardinier, J.D.; Mohamed, F.; Kohn, D.H. PTH signaling during exercise contributes to bone adaptation. J. Bone Miner. Res. 2015, 30, 1053-1063. [CrossRef]

42. Pacheco-Costa, R.; Davis, H.M.; Atkinson, E.G.; Katchburian, E.; Plotkin, L.I.; Reginato, R.D. Osteocytic connexin 43 is not required for the increase in bone mass induced by intermittent PTH administration in male mice. J. Musculoskelet. Neuronal Interact. 2016, 16, 45.

43. Harrison, R.; Ward, K.; Lee, E.; Razaghi, H.; Horne, C.; Bishop, N.J. Acute bone response to whole body vibration in healthy pre-pubertal boys. J. Musculoskelet. Neuronal Interact. 2015, 15, 112. [PubMed]

44. Dorneles, I.M.P.; Fucks, M.B.; Fontela, P.C.; Frizzo, M.N.; Winkelmann, E.R. Guarana (Paullinia cupana) presents a safe and effective anti-fatigue profile in patients with chronic kidney disease: A randomized, double-blind, three-arm, controlled clinical trial. J. Funct. Foods 2018, 51, 1-7. [CrossRef]

45. Santos, J.; Gotardo, E.; Brianti, M.; Piraee, M.; Gambero, A.; Ribeiro, M. Effects of yerba maté, a plant extract formulation ("YGD") and resveratrol in 3T3-L1 adipogenesis. Molecules 2014, 19, 16909-16924. [CrossRef]

46. Wang, Y.; Kerrick, W.G. The off rate of $\mathrm{Ca}\left({ }^{2+}\right)$ from troponin $\mathrm{C}$ is regulated by force-generating cross bridges in skeletal muscle. J. Appl. Physiol. 2002, 92, 2409-2418. [CrossRef]

47. Oliveira, E.P. Runner's diarrhea: What is it, what causes it, and how can it be prevented? Curr. Opin. Gastroenterol. 2017, 33, 41-46. [CrossRef] 
48. Lee, J.; Lee, K.; Song, C. Determining the posture and vibration frequency that maximize pelvic floor muscle activity during whole-body vibration. Med. Sci. Monit. Int. Med. J. Exp. Clin. Res. 2016, 22, 4030. [CrossRef]

49. De Boo, J.; Hendriksen, C. Reduction strategies in animal research: A review of scientific approaches at the intra-experimental, supra-experimental and extra-experimental levels. Atla-Nottingham 2005, 33, 369. [CrossRef] 